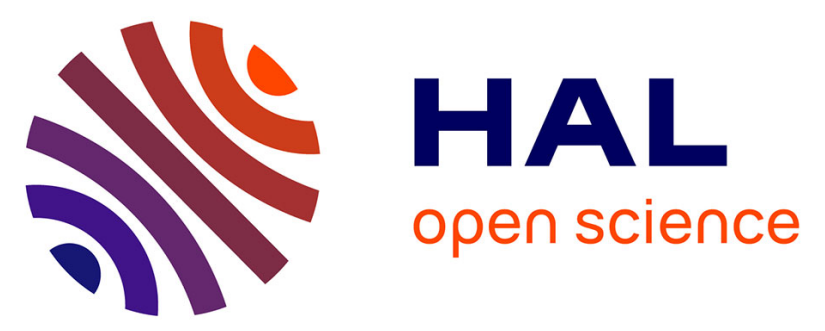

\title{
Innovation in bone technology and artefact types in the late Upper Palaeolithic of China: Insights from Shuidonggou Locality 12
}

Shuangquan Zhang, Luc Doyon, Yue Zhang, Xing Gao, Fuyou Chen, Ying Guan, Francesco d'Errico

\section{To cite this version:}

Shuangquan Zhang, Luc Doyon, Yue Zhang, Xing Gao, Fuyou Chen, et al.. Innovation in bone technology and artefact types in the late Upper Palaeolithic of China: Insights from Shuidonggou Locality 12. Journal of Archaeological Science, 2018, 93, pp.82-93. 10.1016/j.jas.2018.03.003 . hal02864064

\section{HAL Id: hal-02864064 \\ https://hal.science/hal-02864064}

Submitted on 22 Feb 2022

HAL is a multi-disciplinary open access archive for the deposit and dissemination of scientific research documents, whether they are published or not. The documents may come from teaching and research institutions in France or abroad, or from public or private research centers.
L'archive ouverte pluridisciplinaire HAL, est destinée au dépôt et à la diffusion de documents scientifiques de niveau recherche, publiés ou non, émanant des établissements d'enseignement et de recherche français ou étrangers, des laboratoires publics ou privés. 


\section{Innovation in bone technology and artefact types in the Late Upper Palaeolithic of China:}

insights from Shuidonggou Locality 12

Zhang Shuangquan ${ }^{1 *}$, Luc Doyon ${ }^{2,3}$, Zhang Yue ${ }^{1}$, Gao Xing ${ }^{1}$, Chen Fuyou ${ }^{1}$, Guan Ying ${ }^{1}$, Francesco d'Errico ${ }^{2,4^{*}}$

${ }^{1}$ Key Laboratory of Vertebrate Evolution and Human Origins, Institute of Vertebrate Paleontology and Paleoanthropology, Chinese Academy of Sciences, Beijing 100044, China

${ }^{2}$ Centre National de la Recherche Scientifique, UMR 5199 - PACEA, Université de Bordeaux, Bât. B18, Allée Geoffroy Saint Hilaire, CS 50023, 33615 Pessac Cedex, France

${ }^{3}$ Department of Anthropology, Université de Montréal, C.P. 6128, succursale Centre-Ville, Montréal, Québec, Canada, H3C 3J7

${ }^{4}$ SSF Centre for Early Sapiens Behavior (SapienCe), University of Bergen, Øysteinsgate 3, Postboks 7805, 5020, Bergen, Norway.

Corresponding authors: zhangshuangquan@ivpp.ac.cn ; francesco.derrico@u-bordeaux.fr

Key Laboratory of Vertebrate Evolution and Human Origins, Institute of Vertebrate Paleontology and Paleoanthropology, Chinese Academy of Sciences, Beijing 100044, China Email address: zhangshuangquan@ivpp.ac.cn

Centre National de la Recherche Scientifique, UMR 5199 - PACEA, Université de Bordeaux, Bât. B18, Allée Geoffroy Saint Hilaire, CS 50023, 33615 Pessac Cedex, France Email address: francesco.derrico@u-bordeaux.fr 
23

\section{Abstract}

Information on Palaeolithic bone technology from China is sparse. Here we present the results of a techno-functional analysis of a bone tool assemblage recovered from Shuidonggou Locality 12 (SDG12), layer 11, Northern China, dated to c. 12-11 cal ka BP. Five bone tool artefact types are identified: wedges, awls, spear points, a knife handle, a possible sewing implement, and a notched carpal. Two other artefacts could not be attributed to a specific type.

The artefacts are made of Procapra przewalsikii, Lepus sp., Sus sp., Equus przewalskii, and unidentifiable bone fragments from medium/large size mammals. At least three methods are used to extract blanks: percussion of altered limb bones, longitudinal splitting of Sus sp. canine and large rib, and probably, the groove-and-splinter technique. Grinding and scraping are the dominant shaping techniques together with grooving, notching, polishing, drilling, flaking, and retouching. Tool type variability and function fit the hypothesis according to which the SDG12 and similar sites would be residential camps in which hunter-gatherers produced artefacts enabling them to cope with cold environmental conditions. Our results, however, indicate that not all bone tools match the expectations associated with a serial specialist production. Expedient wedges and awls may have been produced by any member of the group, and whenever the need arose. The SDG12 bone tool assemblage provides a significant contribution to our knowledge about hunter-gatherer adaptations to the Tardiglacial environments of Northern China.

Keywords: Bone Tools; Specialized tool-kit; Sewing Equipment; Knife handle; Tardiglacial; 


\section{Highlights}

46

47

- We analyze the most abundant Tardiglacial bone tool assemblage from Northern China

- Five artefact types and three methods to extract blanks are identified

- Blanks were shaped into tools with eight different techniques

- Typological and functional variability fits the specialized tool-kit hypothesis

- Artefacts are interpreted as part of a cultural adaptation to cold conditions

\section{Introduction}

Formal bone tools are defined as objects that were cut, carved, polished, or otherwise modified to produce fully shaped implements such as points, awls, harpoons, and wedges (Klein, 1999). Prior to $45 \mathrm{ka} \mathrm{BP}$, only a handful of African and Australian sites have yielded formal bone tools (Brooks et al., 1995; Yellen et al., 1995; McBrearty and Brooks, 2000; Henshilwood et al., 2001; Jacobs et al., 2006; d'Errico and Henshilwood, 2007; Backwell et al., 2008; d'Errico et al., 2012a,b; Campmas et al., 2015; Backwell and d'Errico, 2016; Langley et al., 2016). After 45 ka BP, formal bone tools are found in Eurasia and are particularly abundant in European Upper Palaeolithic toolkits (e.g., Conard and Bolus, 2003; d'Errico et al., 2003, 2012c). Instances of complex bone technologies in other regions of Eurasia, such as China, are rare (Zhang et al., 2016a). Clear evidence for the production of formal bone tools in Northern China comes from Zhoukoudian Upper Cave (Pei, 1939), Xiaogushan (Zhang et al., 1985; Huang et al., 1986; 
Zhang et al., 2010), Shizitan (Song et al., 2016), and Shuidonggou (Guan et al., 2012; Pei et al., 2012; Yi et al., 2013). Sites that yielded formal bone tools in Southern China include Chuandong (Zhang, 1995; Mao and Cao, 2012), Maomaodong (Cao, 1982), Zhadong (Chen et al., 2004), and Ma'anshan Cave (Zhang et al., 2016a), etc. The technology of these early bone artefacts is often insufficiently documented and their function remains hypothetical (Mao and Cao, 2012 and references therein). In China, the newly published analysis of the bone tools from Ma'anshan Cave, Guizhou province, represents one of the first attempts to describe in detail this category of Palaeolithic material culture (Zhang, et al., 2016a). It identifies evolutionary trends in bone technology from 35 to $18 \mathrm{ka} \mathrm{BP}$, and records the earliest known barbed points outside Africa. In this paper, we analyze another key bone tool assemblage from China, recovered from Shuidonggou Locality 12 (SDG12). Dated to between 12.2 and $11.1 \mathrm{ka}$ BP, this assemblage is exceptional for its excellent state of preservation and the variety of tool types it comprises. Photographs of selected artefacts from this assemblage appeared in the literature (Yi et al., 2013, 2014; Zhang et al., 2016b). However, no detailed technological analysis of key artefact types has been published except for some needles (Zhang et al., 2016b). Our analysis highlights technological features peculiar to the Ordos Plateau and artefact types previously unrecorded at Palaeolithic sites from Asia. It also represents a unique opportunity to document formal bone tool types found in association with microlithic technologies ( $c f$. , Wang, 2005).

It has been proposed that microblade technologies, grindstones, and specific bone tools found at this and other sites represent an adaptation to the cold environments of the LGM and the Younger Dryas in the loessic landscapes of Northeast Asia (Chen, 1983; Yi et al., 2013). Slotted 
bone handles fitted with microblades, bone needles, awls, and technologies devoted to the manufacture of hunting nets would have been used to procure rabbit skins and produce sophisticated winter clothing (Yi et al., 2013). As far as bone technology is concerned, this interpretation is only based on a preliminary description of a few bone tools without documenting the technologies and know-how involved in the production of the bone artefacts found at the site.

The aim of the present paper is to reconstruct these aspects of human behaviour and identify the function for key categories of bone artefacts recovered at SDG12. This will allow us to test, on a category of material culture other than lithics, the pertinence of the "serial specialist" hypothesis (Binford, 1980, p. 17), i.e., the idea that the SDG12 hunter-gatherers subsistence strategy would have relied on standardized tool production to face seasonal challenges in the Tardiglacial environments of Northern China (Yi et al., 2013).

\section{Archaeological context}

\subsection{Site location, stratigraphy, and chronology}

Located on the second terrace of the Biangou River floodplain (Ningxia Hui Autonomous Region, Northern China), $3 \mathrm{~km}$ south-east from the well known Shuidonggou Locality 1 (Licent and Teilhard de Chardin, 1925; Boule, 1928; Pei et al., 2012), SDG12 is an open-air site discovered in 2005 during an archaeological survey of the exposed river bank (Liu et al., 2008;

Gao et al., 2009; Pei, et al., 2012; Yi et al., 2013). In 2007, salvage excavation was carried out over a $12-\mathrm{m}^{2}$ area and a depth greater than $9 \mathrm{~m}$. A total of twelve geological layers were identified based on granulometry and sediment colour (Fig. 1). Archaeological material was only 
recovered from the c. 50-centimetre-thick ashy layer 11, all other layers being sterile. Sediments from this layer were sieved with a 2-milimetre mesh. The layer was further subdivided into five sub-levels, level 1 (youngest) to 5 (oldest). Lithics from these sub-levels are typologically and technologically similar, and are considered as a single assemblage (Yi et al., 2013). The dating of a charcoal from the middle part of layer 11 provided a ${ }^{14} \mathrm{C}$ age of $9,797 \pm 91 \mathrm{BP}(11,164-11,378$ cal BP). OSL ages from layers 10 and 12 are consistent with the ${ }^{14} \mathrm{C}$ determination when the standard error is taken into account (Liu et al., 2008). These ages suggest that the site was occupied toward the end of, or immediately after, the Younger Dryas Cold Event (c. 12,900 11,700 cal BP; Rasmussen et al., 2014).

\subsection{Lithic Technology}

The SDG12 lithic assemblage, comprising more than 9,000 pieces, is typical of the Late Pleistocene microlithic industries found in China (Gao et al., 2009; Pei et al., 2012; Yi et al., 2013, 2016) and in adjacent regions from Central Asia to Alaska (Goebel, 2002; Brunet, 2012;

Gómez Coutouly, 2012; Tabarev, 2012; Takakura, 2012; Kato, 2014). It is dominated by microblade cores and highly standardized microblades, which were likely obtained by pressure flaking (Pelegrin, 2012), but also includes end-scrapers, notches, points, borers, and burins (Gao et al., 2013; Yi et al., 2013). A variety of grinding tools are represented (Yi et al., 2013). A fragment of an axe and small discs, shaped by grinding, were also found as well as a large number $(>13,000)$ of burnt stone fragments (Gao et al., 2013). The lithic assemblage composition indicates that stone knapping, osseous tool shaping, plant processing, and woodworking were 
125

126

127

128

129

130

131

132

133

134

135

136

137

138

139

140

141

142

143

carried out at the site (Yi et al., 2013, 2014).

\subsection{Faunal Assemblage and Taphonomy}

The faunal assemblage comprises more than 10,000 remains, 1,821 of which were identified to species, or to order for microfauna. Lepus sp. (57.4\%) dominates the faunal spectrum followed by Procapra przewalskii (22.2\%), Bubalus sp. (6.8\%), Meles meles (5.7\%), Equus przewalskii (2.9\%), and birds (2.9\%). The remaining $2.1 \%$ of the NISP is composed of Cervidae, Sus sp., Felis microtus, rodents and a single remain of a reptile (Zhang et al., 2013). Cut-marks are present on $5.1 \%$ of the NISP, a proportion similar to that observed at other Chinese Late Pleistocene sites analyzed with comparable methods, e.g., Ma'anshan Cave (Zhang et al., 2010). Carnivore and rodent modifications were only detected on four pieces. This combined evidence suggests that the faunal assemblage is mainly the result of anthropogenic activities. Root etching is the main post-depositional alteration. Although fluvial action is considered a key factor in the formation of this site (Liu et al., 2008) no obvious modification produced by this process were detected on the faunal remains.

\section{Materials and methods}

The osseous industry from SDG12 is curated at the Institute of Vertebrate Palaeontology and Palaeoanthropology of China, Beijing.

Each bone artefact was studied with a Nikon SMZ1500 stereomicroscope at magnifications ranging from $7.5 \mathrm{x}$ and $112.5 \mathrm{x}$. Anthropogenic modifications were distinguished from natural 
ones on the basis of criteria known in the literature (Shipman and Rose, 1983; Behrensmeyer et al., 1986; Lyman, 1994; Fisher, 1995). Identification of manufacturing techniques and use-wear traces was based on observation of ethnographic, experimental, and archaeological bone tools (LeMoine, 1994; Malerba and Giacobini, 2002; d'Errico et al., 2003; Karavanić and Šokec, 2003; Backwell and d'Errico, 2004; Christidou and Legrand, 2005; Griffitts, 2006; d'Errico and Henshilwood, 2007; Legrand and Sidéra, 2007; Gates Saint-Pierre and Walker, 2007; Legrand and Radi, 2008; Mozota Holgueras, 2008, 2009, 2012; Bradfield and Lombard, 2011; Buc, 2011;

Byrd, 2011; Bradfield, 2012; Jéquier et al., 2012; Mallye et al., 2012; Blasco et al., 2013;

Bradfield and Brand, 2013; Daujeard et al., 2014; Hardy et al., 2014; Jéquier, 2014; Moigne et al., 2016; Tejero et al., 2016; Yeshurun et al., 2017). When identifiable, the species and anatomical elements selected as blanks were recorded. Otherwise, an animal size class was estimated from the cortical thickness. Techniques of manufacture, the area where they were applied, and the location and type of use-wear were documented. Morphometric data were collected using digital callipers, and included the maximum length, width, and thickness of the artefact. Identification of tool types has taken into account archaeological and ethnographic data from Europe, Africa, and America, with tentative attributions based on the morphology, size, traces of utilisation, and hafting (LeMoine, 1994; Henshilwood, et al., 2001; d'Errico and Henshilwood, 2007; Gates Saint-Pierre and Walker, 2007; Backwell, et al., 2008; Bradfield, 2010).

\section{Results}


SDG12 (Table 1). Needles (Zhang et al., 2016b) are excluded from the present study, as they will be the focus of a global comparative study. This number differs from a previous publication (Gao et al., 2013) as it also takes into account fragmentary artefacts identified by two of us (ZS, ZY) during the archaeozoological analysis of the sieved material. Five bone tool types were identified: wedges (4), one of which was also used as a retoucher, awls (4), spear points (3), knife handle (1), possible sewing implement (1), notched carpal (1). Two artefacts could not be attributed to a specific tool type. In the following description, we indicate for each object the figure in which it is illustrated followed by the catalogue number as it appears in Table 1.

\subsection{State of preservation}

\subsubsection{Wedges and a retoucher}


recent marginal breaks affecting its proximal and mesial edges (Figure 2 n. 1, cat. 132). The second, also almost complete, displays an ancient proximal break (Fig. 2 n. 2, cat. 4008). The third is incomplete and made of compact bone (Fig. 2, n. 3, cat. 3091). It has a triangular section and tappers to the distal end creating a convex bevel. The fourth is a small distal fragment, bearing recent longitudinal and proximal fractures, but retaining a portion of its original bevel (Figure 2 n. 4, cat. 2857). The blank to produce the first artefact comes from a Procapra przewalskii long bone, possibly the posterior aspect of a radius. The other three wedges were manufactured out of an undetermined long bone from a small/medium size mammal. The blank used to manufacture the wedges were likely obtained by fracturing a weathered bone, as indicated by their longitudinal outline and morphology of the fractures (Lyman, 1994: 315-353). Both scraping and grinding were applied to shape the first tool (Fig. 3a, cat. 132). Scraping was used to regularize the lateral edges (Fig. 3b, cat. 132). The periosteal surface of the bevel was ground following different directions. The endosteal surface was ground obliquely. After utilisation, grinding was applied again, this time parallel to the tool main axis, to resharpen the bevel. Obvious traces of utilisation are detected on the bevel. They take the form of a polish covered by a palimpsest of microstriations perpendicular or slightly oblique to the edge, which is characteristic of an action against sorted abrasive particles (Fig. 3c, cat. 132). A more discrete polish, observed on the lateral edge of the tool, may result from handling or hafting. A group of alligned impact scars, present on the endosteal face close to the proximal fracture, suggests that the tool may have also been used, in a single instance, as a retoucher (Karavanić and Šokec, 2003; Mozota Holgueras, 2008, 2009, 2012; Mallye et al., 2012). 
The blank used to manufacture the second wedge was only slightly modified by removing a series of adjacent microflakes on its right edge (Fig. 2, n. 2, cat. 4008) and by marginally scraping the left edge. The bevel displays a highly polished convex facet on the periosteal surface (Fig. 3d, cat. 4008) and imbricated stepped tangential scars with highly polished ridges on the endosteal surface (Fig. 3e, cat. 4008). The bevel edge features a crenulated outline with tightly closed incipient fractures. The above features likely result from the use of the tool as a wedge exerting either pressure or percussion on hard material. The proximal fracture may have resulted from the break of the tool during its use.

The third wedge was entirely shaped by grinding, including a small facet blunting the

\subsubsection{Awls}


130 and 2850) although the mesial portion of SDG-130 is heavily eroded; they were respectively manufactured from the proximal epiphysis (Figure 2, n. 6, cat. 2850) and the diaphysis (Figure 2, n. 5, cat. 130) of Procapra przewalskii metatarsals. The third artefact comes from a diaphysal fragment of a Lepus sp. long bone (Figure 2, n. 7, cat. 1208). Its proximal portion is missing. A fourth object, shaped on a shaft fragment of a juvenile medium size herbivore, comprises two non-joining mesial-distal fragments (Fig. 2 n. 8, cat. 2859).

The orientation and morphology of the fractures on SDG12-130 suggest that the blank was extracted from a weathered bone in order to obtain an elongated, thin splinter. The resulting blank was slightly shaped at one end by flaking. The other end was scraped and subsequently 
due to a gentle resharpening of the tip by scraping or utilisation. The manufacture of

SDG12-2850 entailed production of the blank by percussion and, subsequently, grinding the

edges and a portion of the periosteal surface. The grinding was exerted perpendicularly and obliquely to the object axis (Fig. 5g, cat. 2850). The constricted morphology of the tip was obtained with the same technique.

\subsubsection{Projectile points}

The three specimens interpreted as projectile points comprise a mesial-distal (Fig. 2, n. 9,

cat. 1211), a mesial (Fig. 2, n. 10, cat. 2854), and a proximal (fig; 2, n.11, cat. 2858) fragment.

Long bone diaphyses of medium size herbivores were selected for the manufacture of the first

two objects. A rib from a similar size class mammal, likely juvenile, was used for the third.

SDG12-1211 was manufactured by obliquely grinding the blank with the exception of the

medullary canal. Traces of grinding were partially obliterated, close to the tip, by longitudinal

scraping resulting in elongated facets (Fig. 6a, cat. 1211). SDG12-2854 was instead shaped by

longitudinally scraping the whole surface (Fig. 6b, cat. 2854) and slightly modifying an area

close to the proximal fracture by grinding (Fig. 6c, cat. 2854). The shaft of SDG12-2858 was

exclusively manufactured by longitudinal scraping (Fig. 6e, cat. 2858). Diagnostic traces of

manufacture are absent on the flat base (Fig. 6d, cat. 2858). However, its morphology and outline

suggest that this area of the object was manufactured by grinding. At the opposite end, the step

fracture is typical of damage resulting from use as projectile point (Pétillon, 2006; Bradfield,

Lombard, 2011; Bradfield and Brand, 2013; Doyon and Knecht, 2014). 
This artefact presents one pointed and one curved end, partially removed by an ancient scar

269

270

271

272

273

274

275

276

277

278

279

280

281

282

283

284

285

286

287

288

(Fig. 2, n. 12, cat. 1213). Its thickness indicates that the blank was extracted from the limb bone

of a medium/large size mammal. Four techniques were used to manufacture the tool. The

preform was given a spindle shape by longitudinal scraping (Fig. 7a, cat. 1213). A perforation

was then made close to one end by drilling both sides of the object. The section of the hole and

the concentric striations covering its surface indicate that the perforation was likely made with a

hafted lithic point (Fig. 7b, cat. 1213). A deep longitudinal groove was subsequently incised,

starting from the hole, and enlarged on both faces until an elongated eye was produced. On both

faces, the groove terminations diverge toward the right. The resulting rods were given a circular

section by scraping. The eye's maximum dimensions are $28.2 \mathrm{~mm}$ (length), $4.9 \mathrm{~mm}$ (width), and

$5.7 \mathrm{~mm}$ (thickness). Finally, the end close to the hole was ground in order to reduce its length and

create a squeezed cone (Fig. 7c-e, cat. 1213). The handling of the object may explain the slight

polish that covers the whole surface. The function of the tool is difficult to establish. However,

its shape is reminiscent of ethnographic implements used in sewing activities (see discussion).

\subsubsection{Handle}

Reconstructed from six fragments, this elongated artefact is almost complete apart from

recent fractures affecting one end and, to a lesser extent, both lateral edges (Fig. 2, n.13, cat.

141). It was manufactured from a rib of a large mammal, split longitudinally. The artefact bears

traces of intense polishing that have obliterated marks left by the shaping of the blank. By

comparison with fragments of modified ribs from the same assemblage to produce needles, the

object was likely modified by grinding the trabecular tissue and scraping the compact bone 
before regularizing the surface by polishing. One edge was carefully grooved, probably to insert straight bladelets (Yi et al., 2013). The groove is $80.9 \mathrm{~mm}$ long, $2 \mathrm{~mm}$ wide, and $3.5 \mathrm{~mm}$ deep. A well-defined longitudinal incision was engraved on each side of the object, a millimetre apart from the opposite edge (Fig. 8a, cat. 141). Two sets of fifty and forty-six equidistant notches were cut between these incisions, creating a ladder-like motif (Fig. 8b, cat. 141). The size and outline of the notches suggest that both sets were made in a single session with the same cutting edge. They are heavily worn by the handling of the tool. Their cross-section is too superficial to be documented.

\subsubsection{Notched carpal}

This artefact is a horse (Equus przewalskii) left third carpal with a recent break removing a fragment on its posterior aspect (Fig. 2, n. 14, cat. 2855). Root etching has heavily altered its surfaces. However, traces of intentional grinding are visible on the distal articular face of the object and at least seven parallel notches were cut on its anterior proximal margin (Fig. 9a, cat. 2855). Due to its state of preservation and the loose structure of the bone, it is problematic to establish whether the notches were made by a single or by multiple cutting edges. A difference in patina is observed between the outer bone surface and that of the notches suggesting the latter were made when the bone was already partially fossilized.

\subsubsection{Undetermined}

Piece SDG12-1215 is a refitted mesial fragment of a rod bearing recent proximal, distal, and longitudinal fractures (Fig. 2, n15. cat. 1215). It was manufactured on the diaphysis of a medium size mammal. The object is triangular in section. It bears traces of longitudinal scraping, partially 
erased by polishing (Fig. 9b, cat. 1215). Intense grinding has gently tapered one end of the piece (Fig. 9c, cat. 1215).

Piece SDG12-3266 (Fig. 2, n16, cat. 3266) is a mesial fragment of a wild boar (Sus sp.) canine with recent fractures on both ends. It is triangular in section with a face retaining the enamel, the second displaying the occlusal wear facet, and the third showing a deliberate modification by intense grinding exerted perpendicularly to the object main axis (Fig. 9d, cat. 3266).

\section{Discussion and conclusion}

Upper Palaeolithic sites from Northern China have only yielded few bone tools and a limited number of artefact types, e.g., Shizitan Locality 29 (Song et al., 2016), Shuidonggou Locality 2 (Guan et al., 2012), and Xiaogushan (Huang et al., 1986). The paucity of large and well-preserved bone tool assemblages and the loss of the abundant collection from Zhoukoudian Upper Cave (Pei, 1939) offered limited opportunities to conduct technological and functional analyses of this category of prehistoric material culture in this region. The rich assemblage from SDG12 now makes this endeavour possible.

The SDG12 bone tools were manufactured with a wide array of techniques. The few cases in which the species could be identified testify to the selection of skeletal elements from the two predominant taxa in the faunal assemblage, i.e., Procapra przewalskii and Lepus sp. The cortical thickness and morphology of most of the other bone artefacts indicate that Procapra przewalskii 
long bones may have been used for their manufacture. Four artefacts were produced from

skeletal elements of larger mammals, which are marginally represented in the faunal assemblage; this is the case for the ground Sus sp. canine, the notched Equus przewalskii carpal, the possible sewing implement made out of a robust limb bone, and the handle manufactured from a large rib.

At least three methods were used to extract blanks at SDG12. Most of them resulted from the percussion of slightly altered limb bones, which produced elongated blanks. Judging from the morphology of the fractures, this may also be the case for the awl shaped on a proximal fragment of a Procapra przewalskii metatarsal (Fig. 2, n. 6). The second technique entails the longitudinal splitting of a large rib. This technique was used to extract the blank employed to manufacture the handle (Fig. 2 n. 13). A similar technique may have been used to reduce the wild boar canine.

The canines of suids can be easily split longitudinally by percussion and, when weathered, often already present longitudinal cracks that facilitate this task (d'Errico et al., 2012 c). Finally, few blanks were probably obtained by applying the groove-and-splinter technique (Fig. 2, n. 9, 10, \& 12). The production of the slot on the handle and the eye on the possible sewing implement indicate that longitudinal grooving, essential for the production of blanks with this technique, was well-mastered at SDG12.

Grinding and scraping are the dominant shaping techniques. When it was possible to establish the order in which both were applied, scraping precedes grinding. The only exception is a projectile point (Fig. 2 n. 9) on which marginal scraping applied to the tool tip may be due to its resharpening. The systematic use of grinding documented at SDG12 is consistent with what has 
been observed at other Asian sites (Rabett and Piper, 2012; O'Connor et al., 2014; Aplin et al.,

2016; Perera et al., 2016; Zhang et al., 2016a). In contrast, this technique is virtually absent in the

Upper Palaeolithic of Western Europe (Camps-Fabrer, 1976; Langley, 2016), with the possible

exception of a single Uluzzian awl from Grotta del Cavallo, layer E III (d'Errico et al., 2012b).

Although it has been proposed that grinding was applied to osseous material in the Gravettian of

Eastern Europe (Goutas 2004, 2013), supporting evidence is limited. In Africa, grinding is

relatively rare in the Middle Stone Age (d'Errico and Henshilwood, 2007; Backwell and 
and ethnographic specimens. The fragmentary state of others (Fig. 2 n. 15 \& 16) prevents a functional interpretation. The artefact interpreted as a handle does not show microblades in its groove. However, its strong technological and morphological similarity with known complete, more recent knife handles from Xiliang, dated to c. 8.5 ka BP (Liu, 2007), Shangzhai, dated to 7.9-6.6 ka BP (Cui et al., 2010), and Dadiwan, dated to 7.9-6.0 ka BP (Yi et al., 2013; Bettinger et al., 2015), clearly indicates that we are dealing with the same tool type, which apparently was used almost unchanged for at least 4,000 years in Northern China. If highly standardized microblades are taken as an archaeological proxy for a technological system that includes the production of composite knives, the SDG12 object (Fig. 2 n. 13) may represent a rare instance of a long-term tradition going back to the very appearance of microblades in China. In such technological system, standardized microblades obtained by pressure flaking would facilitate the repair of the knife cutting edge. The minute, careful decoration visible on this object may signal group affiliation or personal ownership (Wiessner, 1983; Barton, 1997; Bar-Yosef, 2002), which, if one accepts the association handle-microblades hypothesis, may have been at work in China as early as $30 \mathrm{ka} \mathrm{BP.}$

We have found no obvious ethnographic comparisons for the possible sewing implement. Shuttles used for net making either bear two opposite deep indentations, or one pointed and one concave end associated with an eye longitudinally crossed by a prong (Keddie, 2010; Bless et al., 2015). Although none of these features are visible on our object, its round shape and the careful application of two manufacturing techniques fit the interpretation of a tool used in domestic 
activities, perhaps in combination with needles to produce tight seams, or for net making (Yi et al., 2013). No such tool have been reported from Upper Palaeolithic contexts in Eurasia, where weaving and net making would have used bone tools of different morphology (Soffer, 2004).

Our analysis has revealed that many bone artefacts bear indubitable traces of utilisation. A polish on the active area is the main trace of use recorded on wedges, awls, and the possible sewing implement. A polish possibly due to hafting and handling was recorded on a wedge (Fig. 2, n. 2) and the knife handle respectively (Fig. 2, n. 13). In the case of the possible sewing implement eye, the use wear slightly deformed its original outline (Fig. 2, n. 12). Other traces of use include crenulation of the wedges' active edge (Fig. 2, n. $2 \& 4$ ) and tangential flake scars due to percussion (Fig. 2 n. 3). The projectile point made out of a rib (Fig. 2 n. 11) displays a step fracture typical of hafted armature broken on impact. Finally, one wedge was also used as a retoucher in a single occasion (Fig. $2 \mathrm{n} .1$ ). The differences in the types of use-wear recorded on the wedges suggest that a functional distinction must be made for at least one specimen (Fig. $2 \mathrm{n}$. 1). The polish characteristic of an action against sorted abrasive particles observed on SDG12-132 (Fig. 3d) could indicate it was used as an end-scraper in activities such as hide working (Christidou and Legrand, 2005), while the others (Fig. 2 n. 2-4) were likely used as cleaver as attested by the crenulations and flake scars present on their bevel.

In summary, SDG12 bone assemblage demonstrates a remarkable mastery of the techniques known in prehistory to modify osseous materials and, in a number of respects, a know-how of a complexity comparable to that known in the European Upper Palaeolithic. The technological and 
morphological variability observed in typologically analogous tools (e.g., wedges, awls, points) suggests that these artefacts represent instances of a much broader variability. This diversity in tool types and forms gives the impression that we have an incomplete view of the bone artefacts brought to, manufactured, used, and lost or disposed at the site. Some wedges, for example, fall in the category of fully modified formal tools (e.g., end-scraper) while others are better described as expedient tools (e.g., cleavers). Some awls have very sharp active areas while others are sturdier. Very specialized artefacts such as the possible sewing implement, the knife handle, the notched carpal, and the ground Sus sp. canine correspond to single instances of clearly distinct artefact types.

These observations are only partially consistent with the recently proposed hypothesis according to which the SDG12 toolkit would reflect a cultural adaptation to the cold environments of the Tardiglacial. According to this hypothesis, SDG12 is interpreted as a residential camp site in which hunter-gatherers would have prepared themselves for winter by carrying out a variety of activities (e.g., hunting, carcass processing, sewing clothes, net making, processing plants, etc.). The production of specialized highly effective cultural items would have been guaranteed by "serial specialists" i.e., members of the group detaining the know-how allowing them to produce highly standardized artefacts such as microblades (Yi et al., 2013). The technology used to manufacture a number of tools involved shaping by grinding, which may have been performed on the numerous grinding tools found at the site. The functions for which the SDG12 bone tools were likely used (e.g., hunting, skin cutting and processing, sewing 
clothes, net knitting, etc.) fit the residential hypothesis and the idea that the osseous toolkit was an effective adaptation to the cold environment (Goebel, 2002). However, not all bone tools

match the expectations associated with a serial specialist production, i.e., highly standardized tool

produced, possessed, and transported by a specialist. While the knife handle and the possible

sewing implement could fit this interpretation, any member of the group could have produced the

expedient wedges and awls whenever the need for such tools arose. This distinction can be

explained by the fact that high quality lithic raw material for the manufacture of microblades

were transported to the site and processed by specialized knappers, while many bone tools were

likely manufactured from readily available carcasses, then used and discarded at the site. We are

clearly witnessing a complex technical system in which different know-hows are required to

accomplish a wide variety of tasks. In order to better understand the behavioural complexity

necessary for the production and use of bone tools in these tasks, we would need a richer bone

assemblage including a greater number of specimens for each tool type and, ideally, by-products

of their manufacture. The SDG12 bone tool assemblage nevertheless provides a significant

contribution to our knowledge on hunter-gatherer adaptation to the Tardiglacial environments of the

Ordos Plateau of China.

\section{Acknowledgments}

446 We thank the anonymous reviewers for their constructive suggestions. This work was funded by

447 grants from the National Natural Science Foundation of China (41672023, 41772025), and the

448 Sino-French Cai Yuanpei Program (36707NF). This work was partially supported by the 
Research Council of Norway through its Center's of Excellence funding scheme, SFF Centre for

Early Sapience Behaviour (SapienCe), project number 262618 and by the Labex

LaScArBx-ANR n ${ }^{\circ}$ ANR-10-LABX-52.

\section{Reference cited}

Aplin, K., O’Connor, S., Bulbeck, D., Piper, P.J., Marwick, B., Pierre, E.S., Aziz, F., 2016. The Walandawe Tradition from Southeast Sulawesi and Osseous Artifact Traditions in Island Southeast Asia. In: Langley, M.C. (Ed.), Osseous Projectile Weaponry: Towards an Understanding of Pleistocene Cultural Variability. Springer Netherlands, Dordrecht, pp. 189-208.

Backwell, L.R., d'Errico, F., 2004. The first use of bone tools: a reappraisal of the evidence from Olduvai Gorge, Tanzania. Palaeontol. Afr. 40 (9), 95-158.

Backwell, L., d'Errico, F., 2016. Osseous Projectile Weaponry from Early to Late Middle Stone Age Africa. In: Langley, M.C. (Ed.), Osseous Projectile Weaponry: Towards an Understanding of Pleistocene Cultural Variability. Springer Netherlands, Dordrecht, pp. $15-29$.

Backwell, L., d'Errico, F..,Wadley, L., 2008. Middle Stone Age bone tools from the Howiesons Poort Layers, Sibudu Cave, South Africa. J. Archaeol. Sci. 35 (6), 1566-1580.

Bar-Yosef, O., 2002. The upper paleolithic revolution. Annu. Rev. Anthrop. 31 (1), 363-393.

Barton, C.M., 1997. Stone tools, style, and social identity: an evolutionary perspective on the archaeological record. Arch. P. Amer. Ant. Asso. 7 (1), 141-156. 
Behrensmeyer, A.K., Gordon, K.D., Yanagi, G.T., 1986. Trampling as a cause of bone surface damage and pseudo-cutmarks. Nature 319 (6056), 768-771.

Bettinger, R.L., Morgan, C., Barton, L., 2015. The North China Nanolithic. In: Goodale, N., Andrefsky, J.W. (Eds.), Lithic Technological Systems and Evolutionary Theory. Cambridge University Press, New York, pp. 100-116.

Binford, L.R., 1980. Willow smoke and dog's tails: hunter-gatherer settlement systems and archaeological site formation. Amer. Ant. 45, 4-20.

Blasco, R., Rosell, J., Cuartero, F., Peris, J.F., Gopher, A., Barkai, R., 2013. Using bones to shape stones: MIS 9 bone retouchers at both edges of the Mediterranean Sea. PLoS ONE 8 (10), e76780.

Bless M., Fernández N.C., Adovasio J.M., 2015. Did our Late Palaeolithic ancestors use stick shuttles for weaving and netting?. Antiquity 89, 347 [online]. http://archive.antiquity.ac.uk/projgall/bless347.

Boule, M., Breuil, H., Licent, E., Teilhard de Chardin, P. 1928. Le Paléolithique de la Chine. Archives de l'Institut de Paléontologie Humaine, Vol. 4, Paris..

Bradfield, J., 2010. The evolution of bone points as hunting weapons in South Africa. Master's Dissertation. University of the Witwatersrand, Johannesburg.

Bradfield, J., 2012. Macrofractures on bone-tipped arrows: analysis of hunter-gatherer arrows in the Fourie collection from Namibia. Antiquity 86 (334), 1179-1191.

Bradfield, J., 2016. Bone Point Functional Diversity: A Cautionary Tale from Southern Africa. In: Langley, M.C. (Ed.), Osseous Projectile Weaponry: Towards an Understanding of 
Pleistocene Cultural Variability. Springer Netherlands, Dordrecht, pp. 31-40.

Bradfield, J., Brand, T., 2013. Results of utilitarian and accidental breakage experiments on bone points. Archaeol. Anthrop. Sci. 1-12.

Bradfield, J., Lombard, M., 2011. A macrofracture study of bone points used in experimental hunting with reference to the South African Middle Stone Age. S. Afr. Archaeol. Bull. $66,67-76$.

Brooks, A.S., Helgren, D.M., Cramer, J.S., Franklin, A., Hornyak, W., Keating, J.M., Klein, R.G., Rink, W.J., Schwarcz, H., Smith, J., 1995. Dating and context of three Middle Stone Age sites with bone points in the Upper Semliki Valley, Zaire. Science 268 (5210),

Brunet, F., 2012. The Technique of Pressure Knapping in Central Asia: Innovation or Diffusion?. In: Desrosiers, P.M. (Ed.), The Emergence of Pressure Blade Making-From Origin to Modern Experimentation. Springer, pp. 307-328.

Buc, N., 2011. Experimental series and use-wear in bone tools. J. Archaeol. Sci. 38 (3), 546-557.

Byrd, J.C., 2011. Archaic bone tools in the St. Johns River Basin, Florida: microwear and manufacture Traces. Master's Dissertation. Florida State University, Florida.

Campmas, E., Michel, P., Costamagno, S., Amani, F., Stoetzel, E., Nespoulet, R., Hajraoui, M.A.E., 2015. Were Upper Pleistocene human/non-human predator occupations at the Témara caves (El Harhoura 2 and El Mnasra, Morocco) influenced by climate change? J. Hum. Evol. 78, 122-143.

Camps-Fabrer, H., 1976. Le travail de l'os. In: La préhistoire française t.I. CNRS, Paris, pp. 
717-722.

512 Cao, Z.T., 1982. The preliminary study of bone tools and antler spades from the rock shelter site of Maomaodong. - Acta Anthropol. Sinica 1 (1), 36-41 (in Chinese).

Chen C., 1983. Preliminary exploration of the typology and technology of microcore in China-also of the culture relationship between Northeast Asia and Northwestern North America. - Acta Anthropol. Sinica 2 (4), 331-341 (in Chinese).

Chen, Q., Wang, S., Zhang, D., 2004. A Study of the Faunal Remains from the Qingjiang River. Science Press, Beijing (in Chinese).

Christidou, R., Legrand, A., 2005. Hide working and bone tools: experimentation design and applications. In: L. Heidi, C. Alice M., B. Collen E. and L. Lembi (Eds.), From Hooves to Horns, from Mollusc to Mammoth, Manufacture and Use of Bone Artifacts from Prehistoric Times to the Present-Proceedings of the 4th Meeting of the (ICAZ) Worked Bone Research Group. Muinasaja teadus, Tallin, pp. 385-396.

Conard, N.J., Bolus, M., 2003. Radiocarbon dating the appearance of modern humans and timing of cultural innovations in Europe: new results and new challenges. J. Hum. Evol. 44 (3), $331-371$.

Cui, T., Yang, Q., Yu, J., Zhou, S., Zhao, C., 2010. Microwear analysis of a bone-handled microblade excavated at Shangzhai site in Beijing: Evidences from ESEM. Sci. China Earth Sci. 53 (9), 1335-1342.

d'Errico, F., Backwell, L.R., Wadley, L., 2012a. Identifying regional variability in Middle Stone Age bone technology: The case of Sibudu Cave. J. Archaeol. Sci. 39 (7), 2479-2495. 
d'Errico, F., Borgia, V. and Ronchitelli, A., 2012b. Uluzzian bone technology and its implications for the origin of behavioural modernity. Quat. Int. 259, 59-71.

d'Errico, F., Backwell, L., Villa, P., Degano, I., Lucejko, J.J., Bamford, M.K., Higham, T.F.G., Colombini, M.P., Beaumont, P.B., 2012c. Early evidence of San material culture represented by organic artifacts from Border Cave, South Africa. Proc. Natl. Acad. Sci. 109 (33), 13214-13219.

d'Errico, F., Henshilwood, C.S., 2007. Additional evidence for bone technology in the southern African middle stone age. J. Hum. Evol. 52 (2), 142-163.

d'Errico, F., Julien, M., Liolios, D., Vanhaeren, M., Baffier, D., 2003. Many awls in our argument. Bone tool manufacture and use in the Châtelperronian and Aurignacian levels of the Grotte du Renne at Arcy-sur-Cure. In: Zilhao, J., d'Errico, F. (Eds.), The Chronology of the Aurignacian and of the Transitional Technocomplexes: Dating, Stratigraphies, Cultural Implications: Proceedings of Symposium 6.1 of the XIVth Congress of the UISPP (University of Liège, Belgium, September 2-8, 2001). Instituto Portugués de Arqueología, Lisbon, pp. 247-270.

Daujeard, C., Moncel, M.-H., Fiore, I., Tagliacozzo, A., Bindon, P., Raynal, J.-P., 2014. Middle Paleolithic bone retouchers in Southeastern France: Variability and functionality. Quat. Int. $326,492-518$.

Doyon, L., Knecht, H.K., 2014. The Effects of Use and Resharpening on Morphometric Variability of Aurignacian Antler Projectile Points. Mitteilungen der Gesellschaft für Urgeschichte 23, 83-101. 
Fisher, J.W., 1995. Bone surface modifications in zooarchaeology. J. Archaeol. Method. Th. 2 (1), 7-68.

Gao, X., Wang, H., Pei, S., Chen, F., 2013 Shuidonggou-Excavation and research (2003-2007) report. Science Press, Beijing (in Chinese)..

Gao, X., Wang, H.M., Liu, D.C., Pei, S.W., Chen, F.Y., Zhang, X.L., Zhang, Y., 2009. A study of fire use activities at Shuidonggou Locality 12. Acta Anthropol. Sinica 28 (4), 329-336.

Gates Saint-Pierre, C., Walker, R.B., 2007. Bones as tools: current methods and interpretations in worked bone studies. British Archaeological Reports 1622, Oxford: Oxbow, Oxford.

Goebel, T., 2002. The "microblade adaptation" and recolonization of Siberia during the Late Upper Pleistocene. Arch. P. Amer. Ant. Asso. 12 (1), 117-131.

Gómez Coutouly, Y.A.G., 2012. Pressure microblade industries in Pleistocene-Holocene interior Alaska: current data and discussions. In: Desrosiers, P.M. (Ed.), The Emergence of Pressure Blade Making-From Origin to Modern Experimentation. Springer, pp. 347-374.

Goutas N., 2004. Fiche d'exploitation des matières dures d'origine animale au Gravettien. In: Ramseyer D. (Ed.), Fiches de la Commission de nomenclature sur l'industrie de l'os préhistorique-Cahier XI: Matières et techniques. Paris, Éditions Société Préhistorique Française, p. 53-74.

Goutas N., 2013. Nouvelles données sur l'industrie osseuse des grottes du Renne et du Trilobite à Arcy-sur-Cure (Yonne, France) : vers l'identification de nouveaux marqueurs techniques et culturels du Gravettien moyen à burins du Raysse . In: Bodu, P., Chehmana, L., Klaric, L., Mevel, L., Soriano, S., Teyssandier, N. (Eds.), Le Paléolithique supérieur 
ancien de l'Europe du Nord-Ouest. Réflexions et synthèses à partir d'un projet collectif de recherche sur le centre et le sud du Bassin parisien. Actes du colloque de Sens (15-18 avril 2009), Paris, Société préhistorique française (coll. Mémoire de la Société Préhistorique française, LVI), p. 89-116.

Griffitts, J.L., 2006. Bone tools and technological choice: change and stability on the Northern Plains. Ph.D. Dissertation. University of Arizona, Arizona.

Guan, Y., Gao, X., Li, F. and Pei, S.W., 2012. Modern human behaviors during the late stage of the MIS 3 and the Broad Spectrum Revolution: Evidence from a Shuidonggou Late Paleolithic site. Chinese Sci. Bull. 57 (4), 379-386.

Hardy, M., Bouchard, G.P., Doyon, L., 2014. Un outil en os à usages multiples dans un contexte moustérien. Bull. Soc. Préhist. Fr. 111 (4), 741-744.

Henshilwood, C.S., d'Errico, F., Marean, C.W., Milo, R.G., Yates, R., 2001. An early bone tool industry from the Middle Stone Age at Blombos Cave, South Africa: implications for the origins of modern human behaviour, symbolism and language. J. Hum. Evol. 41 (6), 631-678.

Huang, W.W., Zhang, Z.H., Fu, R.Y., Chen, B.F., Liu, J.Y., Zhu, M.Y., Wu, H.K., 1986. Bone artifacts and ornaments from Xiaogushan site of Haicheng, Liaoning Province. Acta Anthropol. Sinica 5 (3), 259-266 (in Chinese)..

Jacobs, Z., Duller, G.A., Wintle, A.G., Henshilwood, C.S., 2006. Extending the chronology of deposits at Blombos Cave, South Africa, back to 140ka using optical dating of single and multiple grains of quartz. J. Hum. Evol. 51 (3), 255-273. 
Jéquier C.A., 2014. Techno-économie des industries en matières dures d'origine animale entre le Paléolithique moyen et supérieur en Italie orientale et Slovénie. Ph.D Dissertation. Universita degli Studi di Ferrara, Ferrara.

Jéquier, C.A., Romandini, M., Peresani, M., 2012. Les retouchoirs en matières dures animales: une comparaison entre Moustérien final et Uluzzien. C. R. Palevol. 11 (4), 283-292.

Karavanić, I., Šokec, T., 2003. The Middle Paleolithic percussion or pressure flaking tools? The comparison of experimental and archaeological material from Croatia. Prilozi Instituta za arheologiju u Zagrebu 20 (1), 5-14.

Kato, S., 2014. Human dispersal and interaction during the spread of microblade industries in East Asia. Quat. Int. 347, 105-112.

Keddie, G., 2010. Netting Needles of British Columbia. The Midden 42 (3), 9-11.

Klein, R.G., 1999. The Human Career: Human Biological and Cultural Origins . 2nd ed. University of Chicago Press, Chicago.

Langley, M.C., 2016. Osseous Projectile Weaponry- Towards an Understanding of Pleistocene Cultural Variability. Springer Netherlands, Dordrecht.

Langley, M.C., O'Connor, S., Aplin, K., 2016. A > 46,000-year-old kangaroo bone implement from Carpenter's Gap 1 (Kimberley, northwest Australia). Quat. Sci. Rev. 154, 199-213.

Legrand, A., Radi, G., 2008. Manufacture and use of bone points from Early Neolithic Colle Santo Stefano, Abruzzo, Italy. J. Field Archaeol. 33 (3), 305-320.

Legrand, A., Sidéra, I., 2007. Methods, means and results when studying European bone 
industries. In: Gates Saint-Pierre, C., Walker, R. (Eds.), Bones as Tools: Current Methods and Interpretations in Worked Bone Studies. BAR International Series 1622. Oxbow, Oxford, pp. 291-304.

LeMoine, G.M., 1994. Use wear on bone and antler tools from the Mackenzie Delta, Northwest Territories. Amer. Ant. 59 (2), 316-334.

Licent, E., Teilhard de Chardin, P., 1925. Le Paleolithique de la Chine. L' Anthropologie (35), 201-234.

Liu, D.C., Chen, F.Y., Zhang, X.L., Pei, S.W., Gao, X., Xia, Z.K., 2008. Preliminary comments on the paleoenvironment of the Shuidonggou Locality 12. Acta Anthropol. Sinica 27 (4), 295-303 (in Chinese).

Liu, G., 2007. The Xinglongwa culture in relation to other cultures. In: Hu, Y. (Ed.), The Origins of Jades in East Asia: Jades of the Xinglongwa Culture. The Center for Chinese Archaeology and Art at the Chinese University of Hong Kong, Hong Kong, pp. 40-51.

Lyman, R.L., 1994. Vertebrate Taphonomy. Cambridge University Press, Cambridge.

Malerba G., Giacobini G., 2002. Fiche éclats diaphysaires. In: Patou-Mathis M. (Ed.), Retouchoirs, Compresseurs, Percuteurs. Os à impressions et éraillures. Fiches de la Commission de Nomenclature sur l'Industrie de l'Os Préhistorique. Cahier X, Paris, Éditions de la Société Préhistorique Française, pp. 29-38.

Mallye, J. B., Thiébaut, C., Mourre, V., Costamagno, S., Claud, É., Weisbecker, P., 2012. The Mousterian bone retouchers of Noisetier Cave: experimentation and identification of marks. J. Archaeol. Sci. 39, 1131-1142. 
Mao, Y.Q., Cao, Z.T., 2012. A preliminary study of the polished bone tools unearthed in 1979 from the Chuandong site in Puding County, Guizhou. Acta Anthropol. Sinica 31 (4), 335-343 (in Chinese).

McBrearty, S., Brooks, A.S., 2000. The revolution that wasn't: a new interpretation of the origin of modern human behavior. J. Hum. Evol. 39 (5), 453-563.

Moigne, A.-M., Valensi, P., Auguste, P., García-Solano, J., Tuffreau, A., Lamotte, A., Barroso, C., Moncel, M.H., 2016. Bone retouchers from Lower Palaeolithic sites: Terra Amata, Orgnac 3, Cagny-l'Epinette and Cueva del Angel. Quat. Int. 409, 195-212.

Mozota Holgueras, M., 2008. Estudio tafonómico y tecnológico de un útil doble “cincel/retocador”, proveniente del nivel C (Musteriense) de Axlor-Dima, Bizkaia. Zephyrus, 61, 217-224.

Mozota Holgueras, M., 2009. El utillaje óseo musteriense del nivel "D” de Axlor (Dima, Vizcaya): análisis de la cadena operativa. Trabajos de Prehistoria, 66, 28-46.

Mozota Holgueras, M., 2012. El hueso como materia prima: El utillaje óseo del final del Musteriense en el sector central del norte de la Península Ibérica. Ph.D. Dissertation. Universidad de Cantabria, Santander.

O'Connor, S., Robertson, G., Aplin, K.P., 2014. Are osseous artefacts a window to perishable material culture? Implications of an unusually complex bone tool from the Late Pleistocene of East Timor. J. Hum. Evol. 67, 108-119.

Pei, S.W., Gao, X., Wang, H.M., Kuman, K., Bae, C.J., Chen, F.Y., Guan, Y., Zhang, Y., Zhang, X.L., Peng, F., Li, X.L., 2012. The Shuidonggou site complex: new excavations and 
implications for the earliest Late Paleolithic in North China. J. Archaeol. Sci. 39 (12), 3610-3626.

Pei, W.C., 1939. The Upper Cave industry of Choukoutien. Palaeont. Sinica (Ser. D) 9, 1-58.

Pelegrin, J., 2012. New experimental observations for the characterization of pressure blade production techniques. In: Desrosiers, P.M. (Ed.), The Emergence of Pressure Blade Making-From Origin to Modern Experimentation. Springer, pp. 465-500.

Perera, N., Roberts, P., Petraglia, M., 2016. Bone Technology from Late Pleistocene Caves and Rockshelters of Sri Lanka. In: Langley, M.C. (Ed.), Osseous Projectile Weaponry: Towards an Understanding of Pleistocene Cultural Variability. Springer Netherlands,

Pétillon, J.M., 2006. Des Magdaléniens en armes: Technologie des armatures de projectile en Dordrecht, pp. 173-188. bois de cervidé du Magdalénien supérieur de la Grotte d’Isturitz (Pyrénées-Atlantiques), Éditions du Cedarc, Treignes, Belgique (Coll. Artefacts, 10).

Rabett, R.J., Piper, P.J., 2012. The emergence of bone technologies at the end of the Pleistocene in Southeast Asia: regional and evolutionary implications. Camb. Archaeol. J. 22 (01), $37-56$.

Rasmussen, S. O., Bigler, M., Blockley, S P., Blunier, T., Buchardt, S. L., Clausen, H B., Cvijanovic, I., Dahl-Jensen, D., Johnsen, S. J., Fischer, H., Gkinis, V., Guillevic, M., Hoek, W. Z., Lowe, J. J., Pedro, J. B., Popp, T., Seierstad, I. K., Steffensen, J. P, Svensson, A. M., Vallelonga, P., Vinther, B. M., Walker, M.J.C., Wheatley, J., Winstrup, M., 2014. A stratigraphic framework for abrupt climatic changes during the Last Glacial 
period based on three synchronized Greenland ice-core records: refining and extending the INTIMATE event stratigraphy. Quat. Sci. Rev. 106, 14-28.

Shipman, P., Rose, J., 1983. Early hominid hunting, butchering, and carcass-processing behaviors: Approaches to the fossil record. J. Anthropol. Archaeol. 2 (1), 57-98.

Soffer, O., 2004. Recovering perishable technologies through use wear on tools: preliminary evidence for Upper Paleolithic weaving and net making. Curr. Anthrop. 45 (3), 407-413.

Song, Y., Li, X., Wu, X., Kvavadze, E., Goldberg, P., Bar-Yosef, O., 2016. Bone needle fragment in LGM from the Shizitan site (China): Archaeological evidence and experimental study. Quat. Int. 400, 140-148.

Tabarev, A.V., 2012. Blades and microblades, percussion and pressure: Towards the evolution of lithic technologies of the stone age period, Russian Far East. In: Desrosiers, P.M. (Ed.), The Emergence of Pressure Blade Making-From Origin to Modern Experimentation. Springer, pp. 329-346.

Takakura, J., 2012. Emergence and development of the pressure microblade production: a view from the Upper Paleolithic of Northern Japan. In: Desrosiers, P.M. (Ed.), The Emergence of Pressure Blade Making-From Origin to Modern Experimentation. Springer, pp. 285-306.

Tejero, J.M., Arrizabalaga, Á., Villaluenga, A., 2016. The Proto-Aurignacian and Early Aurignacian retouchers of Labeko Koba (Basque Country, Spain). A techno-economic and chrono-cultural interpretation using lithic and faunal data. C. R. Palevol. 15 (8), 994-1010. 
699

700

701

702

703

704

705

706

707

708

709

710

711

712

713

714

715

716

717

718

719

Wang, Y., 2005. The roots of Pleistocene hominids and cultures in China. Science Press, Beijing (in Chinese).

Wiessner, P., 1983. Style and social information in Kalahari San projectile points. Amer. Antiq. 48 (2), 253-276.

Yellen, J.E., 1998. Barbed Bone Points: Tradition and Continuity in Saharan and Sub-Saharan Africa. Afr. Archaeol. Rev. 15 (3), 173-198.

Yellen, J.E., Brooks, A.S., Cornelissen, E., Mehlman, M.J., Stewart, K., 1995. A Middle Stone-Age worked bone industry from Katanda, Upper Semliki Valley, Zaire. Science 268 (5210), 553-556.

Yeshurun, R., Tejero, J.M., Barzilai, O., Hershkovitz, I., Marder, O., 2017. Upper Palaeolithic bone retouchers from Manot Cave (Israel): A preliminary analysis of a (yet) rare phenomenon in the Levant. In: Hutson, J.H., Gaudzinski-Windheuser, S., (Eds.), The Origins of Bone Tool Technologies (Römish-Germanisches Zentralmuseums, 2017), pp.1-9.

Yi, M., Barton, L., Morgan, C., Liu, D., Chen, F., Zhang, Y., Pei, S., Guan, Y., Wang, H., Gao, X., Bettinger, R.L., 2013. Microblade technology and the rise of serial specialists in north-central China. J. Anthropol. Archaeol. 32 (2), 212-223.

Yi, M., Bettinger, R.L., Chen, F., Pei, S., Gao, X, 2014. The significance of Shuidonggou Locality 12 to studies of hunter-gatherer adaptive strategies in North China during the Late Pleistocene. Quat. Int. 347, 97-104.

Yi, M., Gao, X., Li, F., Chen, F., 2016. Rethinking the origin of microblade technology: A chronological and ecological perspective. Quat. Int. 400, 130-139. 
Zhang, J.F., Huang, W.W., Yuan, B.Y., Fu, R.Y., Zhou, L.P., 2010. Optically stimulated luminescence dating of cave deposits at the Xiaogushan prehistoric site, northeastern China. J. Hum. Evol. 59 (5), 514-524.

Zhang, S., d'Errico, F., Backwell, L.R., Zhang, Y., Chen, F., Gao, X., 2016a. Ma'anshan cave and the origin of bone tool technology in China. J. Archaeol. Sci. 65, 57-69.

Zhang, S.S., 1995. A brief study on Chuandong prehistoric site (excavated in 1981). Acta Anthropol. Sinica 14 (2), 132-146 (in Chinese).

Zhang, Y., Gao, X., Pei, S., Chen, F., Niu, D., Xu, X., Zhang, S., Wang, H., 2016b. The bone needles from Shuidonggou locality 12 and implications for human subsistence behaviors in North China. Quat. Int. 400, 149-157.

Zhang, Y., Stiner, M.C., Dennell, R., Wang, C.X., Zhang, S.Q., Gao, X., 2010. Zooarchaeological perspectives on the Chinese Early and Late Paleolithic from the Ma'anshan site (Guizhou, South China). J. Archaeol. Sci. 37 (8), 2066-2077.

Zhang, Y., Zhang, S.Q., Xu, X., Liu, D.C., Wang, C.X., Pei, S.W., Wang, H.M., Gao, X., 2013. Zooarchaeological perspective on the Broad Spectrum Revolution in the Pleistocene-Holocene transitional period, with evidence from Shuidonggou Locality 12, China. Sci. China Earth Sci. 56 (9), 1487-1492.

Zhang, Z.H., Fu, R.Y., Chen, B.F., Liu, J.Y., Zhu, M.Y., Wu, H.K., Huang, W.W., 1985. A preliminary report on the excavation of Paleolithic site at Xiaogushan of Haicheng, Liaoning Province. Acta Anthropol. Sinica 4 (2), 78-92(in Chinese). 


\section{Legends of figures and table}

742 Figure 1: a: location of Shuidonggou Locality 12; b: photo of the stratigraphy indicating the

$$
\text { geological layers and their limits (b, modified after Pei et al. 2012) }
$$

Figure 2: Osseous artefacts from SDG12 layer 11 analysed in this study. Scales $=1 \mathrm{~cm}$. See table 1 for additional information

Figure 3: Traces of manufacture and use on SDG12 wedges; a-c: 132; d-e: 4008; f: 2857. Scales:

$$
\mathrm{a}, \mathrm{b}=1 \mathrm{~mm} ; \mathrm{c}=200 \mu \mathrm{m} ; \mathrm{d} \sim \mathrm{f}=500 \mu \mathrm{m}
$$

Figure 4: Traces of manufacture on wedge SDG12-3091. Scales: $a=1000 u m ; b=500 \mu \mathrm{m}$.

Figure 5: Traces of manufacture and use on SDG12 awls; a-b: 130; c-d: 2859; e-f: 1208; g: 2850.

$$
\text { Scales: } \mathrm{a}, \mathrm{d} \mathrm{g}=1 \mathrm{~mm} ; \mathrm{b}, \mathrm{c}=500 \mu \mathrm{m} ; \mathrm{e}, \mathrm{f}=250 \mu \mathrm{m}
$$

Figure 6: Traces of manufacture and use on SDG12 projectile points; a: 1211; b-c: 2854;

$$
\text { d-e: 2858. Scales: a, c = } 1 \mathrm{~mm} ; \mathrm{b}=500 \mu \mathrm{m} ; \mathrm{d}, \mathrm{e}=250 \mu \mathrm{m}
$$

Figure 7: Traces of manufacture and use on possible sewing implement SDG12-1213. Scales: a, c,

$$
\mathrm{d}, \mathrm{e}=1 \mathrm{~mm} ; \mathrm{b}=20 \mu \mathrm{m}
$$

Figure 8: Traces of manufacture on the knife handle SDG12-141. Scales: $a=1 \mathrm{~cm} ; \mathrm{b}=1 \mathrm{~mm}$ Figure 9: Traces of manufacture on SDG12 artefacts; a: 2855; b-c: 1215; d: 3266. Scales: a = $500 \mu \mathrm{m} ; \mathrm{b} \sim \mathrm{c}=1 \mathrm{~mm} ; \mathrm{d}=500 \mu \mathrm{m}$. The oblique bar in $a$ indicates the area enlarged at the bottom of the figure

Table 1: Descriptive, technological, and morphometric data on SDG12 (layer 11) bone artefacts. 
